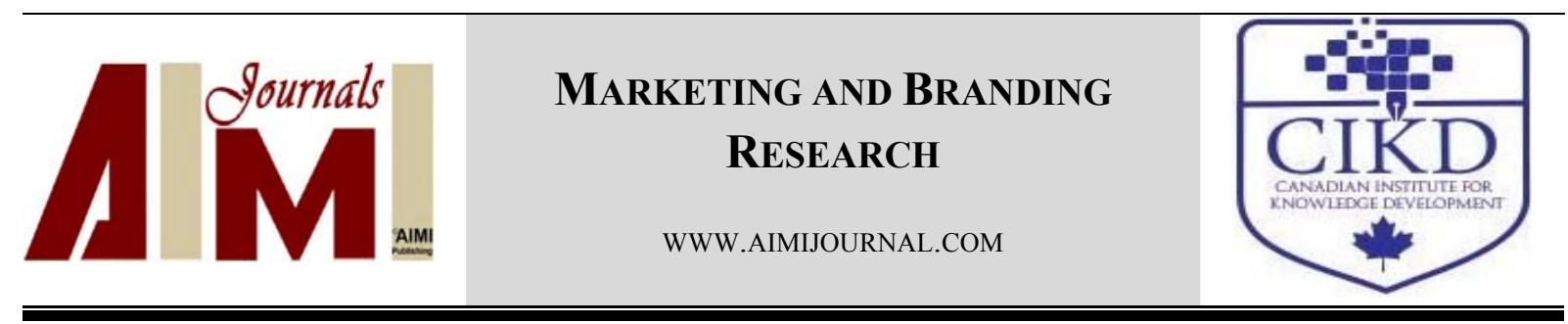

\title{
Higher Education Institutions Embracing Digital \& Social Media Marketing: A Case of Top 25 Universities in Asia \& Africa
}

\author{
Nerisa N. Paladan*, D.B.A \\ Partido State University, Philippines
}

\begin{tabular}{l}
\hline \\
Keywords: \\
Digital, Social Media \\
Marketing, Higher \\
Education Institutions \\
(HEIs) \\
\hline Received \\
24 April 2018 \\
Received in revised form \\
28 September 2018 \\
Accepted \\
30 September 2018 \\
\hline
\end{tabular}

Correspondence: npaladan@gmail.com

\begin{abstract}
At the age of the digital world, higher education institutions (HEIs) are challenged to be creative in reaching out and keeping in touch with their stakeholders and target markets that are mostly the young generation. Businesses and institutions like HEIs should be innovative in attracting customers/students using digital and social media marketing. They have to embrace fully digital and social media marketing in realizing their target market and staying connected with them. This research focused on identifying the common digital and social media marketing utilized by the top 25 universities in Asia and Africa, it also assessed the level of adoption of digital technology. Findings revealed that the majority of the top 25 universities in Asia and Africa use Facebook, Twitter, LinkedIn and YouTube for their digital and social media marketing and they differ in terms of the purposes of its usage and the level of adoption of digital technology. It shows that the collective responses by using digital and social marketing for HEIs are to market their programs and to give information about events and research of the HEIs. However, the majority of the top 25 universities in Asia had already reached fully digital and they use it for visionary production and design for the adoption of digital technology. Furthermore, most of the HEIs are using website design and interface as an essential factor on how to present themselves to their potential students.
\end{abstract}

(C)AIMI Journals

Advancement in technology such as internet can help the HEI's in capitalizing to exploit digital and social media marketing. As higher education institutions find the need to appeal to an ever-increasing and diverse student base, successful outreach and marketing have become increasingly important activities of the institutions. As Kowalik (2011) states that HEIs are 
now looking at the new opportunities and methods to engage with prospective students, alumni and other stakeholders.

In the research conducted by Hanover Research (2014), they refer to "digital" and "social" as the use of both social media and digital marketing more generally, and take into account the role of efficient and insightful websites. In this study, the definition of digital marketing was adopted as strategic decisions of the HEIs where they are increasingly investing by engaging with their target audiences. Therefore, social media engagement for HEIs is about engaging audiences/stakeholders of the universities and driving traffic with the university's website where the ultimate conversions happen. It is also about managing the social presence and gaining audience participation as well as perhaps gaining customer/student feedback through social media marketing. Research shows that there is an increasing number of organizations who are already engaging in social media as part of their marketing strategy (Barnes, 2010; Barnes \& Mattson, 2009). It is also true in the case of higher education institution that are now making larger use of social media and digital platforms like Facebook, Twitter, LinkedIn, YouTube, and podcasts to market their programs, likewise website design and interface are showing an essential factor in how colleges and universities present themselves to prospective students (Hanover Research, 2014).

The present study examined the common digital and social media marketing utilized by the top 25 universities in Asia and Africa. It also identified the purposes of using digital and social media marketing by higher education institutions. Furthermore, it also assessed the HEIs level of adoption of digital technologies. This study may add to the body of knowledge in the discipline of marketing and inspired higher education institution to further develop the opportunities offered by the digital and social media marketing in reaching out and keeping in touch with their stakeholders and target markets that are mostly the young generation.

\section{Trend in Digital and Social Media Marketing}

In the past decade, several social media sites have been developed extremely and higher education institutions could choose among them to implement their outreach campaigns. According to Wikipedia (2012), the most popular social networking sites among young university-age students include Facebook, MySpace, Twitter and YouTube. Those social networking sites have different features such as Facebook has a social function that connects people and friends, MySpace permits the customization of its profile pages, Twitter which combine instant messaging and blogging permits users to "tweets" or send short messages (Reuben, 2008), while LinkedIn is used as a medium for those interested in creating professional and business contacts (Social Media Today, 2011), and YouTube's main function is to upload videos (Pearson Education, 2010).

DigitalBuzz (2012) mentions that over 500 million worldwide users of Facebook with the average of 18-24 years old support the increase at 74\% per year. While the MySpace user has been in a solid decline since 2008, however, it still has over 60 million monthly visitors worldwide (Arrington, 2011). In 2010, approximately Twitter had 100 million distinctive users, with 54\% users in the age range of $25-44$, and LinkedIn had 41 million worldwide participants (Social Media Today, 2011). And lastly, over 1 billion daily views YouTube (Pearson Education, 2010). 
In the study conducted by the University of Massachusetts Dartmouth on the use of social and digital media by universities as part of outreach and marketing it shows that $100 \%$ of respondent institutions are now using some form of social media but it also reveals that there is no reliable data on how effective the use of such tools are in terms of enrolment or elevating institutional value. As to specific platforms used, it reflects a wider adoption of the following social media platforms: Facebook is the most common form of social networking being used, with $98 \%$ of colleges and universities reported having a Facebook page; $84 \%$ reported having some form of an institutional Twitter account; 86\% reported having an institutional YouTube channel/presence; $66 \%$ reported maintaining some kind of blog; 41\% reported the use of podcasting; and $47 \%$ of admissions professionals reported using LinkedIn.

In the study conducted by Merrill (2011), it reveals that social media can be a cost effective recruiting strategy and in 2010 in the study of 30 international university admissions staff it indicated that there was an inclination by institutes to use Facebook (96\%) and Twitter $(66 \%)$ as their outreach tools. $46 \%$ used YouTube and 33\% used LinkedIn. Another study by Slover-Linett and Stoner (2010) reflects that most institutions used social media, with 94\% using Facebook. $60 \%$ of the institutions also used Twitter, LinkedIn, and/or YouTube. 96\% used social media to communicate with alumni, while only about $57 \%$ used it as a marketing tool for perspective students.

\section{Importance of Digital and Social Media Marketing to Higher Education Institutions}

In general, comprehensive social media strategies cannot be found in higher education marketing domain. However, looking at experiences from the business practices (Constantinides, 2010), one could argue that such strategies can provide higher education institutions with new communication possibilities allowing direct engagement with potential students. This engagement can involve interaction with university recruiters or interactions with other students during the process of searching or looking for a suitable study and university. In principle, engaging potential students in the social media domain is an inexpensive way for universities to attract and persuade potential students. Social networks or online communities created by schools as part of their online presence can bring together potential student with students who already enrolled (i.e. 'University Ambassadors' or student leaders), or with peers looking for similar information and help. These engagements were observed to be highly effective ways of encouraging the contemporary consumer. Recommendations of peers in blogs, social networks, forums, and other forms of social media are playing an increasingly important role in the decision making process, mainly among young persons.

Social media is important to the recruiting and marketing functions of an HEI which can have a direct correlation to the institutions success and influence educational policies. According to Anyangwe (2011), online marketing efforts are tied more closely to a university's success. Richard Taylor from the University of Leicester states that "Marketing considerations are now going to align much more clearly with strategic decision making in universities. It was found out in a study about the use of social networking system as a marketing tool by universities that there is a significant relationship between those logged 
onto social networks and the likelihood of applying to the university (Hayes, Ruschman, \& Walker, 2009).

It has a positive effect to stakeholders in the education process once it has a successful electronic marketing and recruiting strategy. Wootton (2011) states that online marketing will play an increasing strategic role in reaching prospective students, especially among for-profit institutions. Another area of social media usage that can affect the educational strategy of HEIs is the recruitment of foreign students. As tuition and fees increase in many countries, HEIs are more often relying on recruiting international students who can pay higher fees and thus subsidize part of university financial success. Wheeler (2012) claims that recruiting international students using social media recruiting and marketing are becoming critical. Accepting more international students can result in more positive educational experiences not only for the international students, but also for domestic students who are exposed to global perspectives. Thus, use of social networking can offer HEIs a more effective method of recruiting international students.

HEIs are boosting its presence on social media sites such as YouTube, and utilizing the most of its potential for marketing and a learning tool and it suggests that HEIs can have multiple sites to address different customer demographics, departments, and functions (Gilroy, 2010). It was late 2009 when YouTube initiates a specific section intended for academic content, where university professionals can upload educational, marketing and other contents to students and other users (Gilroy, 2010). This site becomes the most popular social networking site in which schools use as a communication tool with students (Pearson Education, 2010). According to Ratliff (2011), the opportunity to create sub-channels that are content specific, also creating podcasts of informational materials can be provided by YouTube. For recruiting non-traditional or online students, it was suggested that twitter may be better suited them and HEIs should manage specifically tailored Twitter accounts for different consumer demographics (Mansfield, 2009). LinkedIn addresses specific needs of higher education that could serve as a potential method of direct communication for those aiming to further their education and seek formal qualification, since higher education institutions are now moving towards a more commercial sector (LinkedIn, 2012). As from April 2012, over three and half thousand universities worldwide have an official presence on Facebook (4ICUb). Prospective students or stakeholder who view a university's page on Facebook can choose to become a 'fan' of the institution, which shows their personal profile page, allowing them to access to information about the university. It can create a viral marketing effect, wherein friends are also likely to become fans of the university (Reuben, 2008).

Online marketing through social media offers a cost-effective alternative at a time when many universities cannot rely so heavily on public funding. They are under increasing pressure adopting creative ways to control costs while still maintaining a high level of service. 


\section{Higher Education Institutions, Challenges in Utilizing Digital and Social Media Marketing}

The use of social networking has been growing tremendously over the past several years, its use is not without drawbacks. It may not be totally effective if switching to mainly online marketing campaign, it would be better to have a more diverse set of promotional channels that could lead to reducing costs and providing better value for money. Merrill (2011, p. 41) expresses concerns about the ambiguous feedback from social networking, marketing and the difficulty in measuring results. Given the relatively recent application of the technology, university staff has little guidance or information on effective online marketing and recruiting strategies. Lewis (2010) states that professionals are enduring a 'trial by fire' method to learn how to use social media effectively as a strategic communication method. It was difficult to keep abreast of the constant stream of new products, services and innovation because of the dynamic nature of the technology and sites. Griffiths and Wall $(2011$, p. 64) state that careful monitoring of social sites is critical, and procedures and standards to manage information on sites should be continually reviewed and revised.

HEIs must take note that social media marketing will flourish only if it is based on firm foundations such as innovative and high quality products, and market oriented organizations (Contantinides, 2010). Lewis (2010) noted that social media needs a radically different mindset from traditional media planning. That also includes understanding the technology. University staff would need to appreciate new marketing techniques and the difference from traditional printed based methods. It has an implication for students even if they were early adopters and heavy users of social media. Students may not necessarily make connections to social media strategically (Lewis, 2010) and they will therefore require to acquire and adopt a new skill set to achieve this. Also, those future students might be interested in social interaction and information seeking when using social media. The context used in most social outreach programs is restricted to video and photo sharing in contrast to social interaction. Social media has a high impact among students but its impact on their choice of institution is low compared to traditional forms of university marketing (Constantinides \& Zinck-Stagno, 2011). With almost all cultural change, education is key to staff and students using social media effectively. University officials should play a key role in affecting this change to confirm social media as strategic communication tools.

\section{Different Levels of HEI's Digital Adoption}

According to Dr. Tahir Rashid, some organizations perhaps are at the beginning stage of adopting technology, while others may be quite mature. Within the digital environment, there are different levels that organizations go through that is also applicable to HEIs. For example, at Level 0, HEI's may have very minimum presences on the Internet - and this is, not by their own initiative. In Level 1, HEI's has made some attempt to have a digital presence in terms of their academic programs and services. Level 2, they are now going to the next stage where they are beginning to have much more presence than, say, Level 1. HEI's is trying to optimize some of its operation digitally while other operations may be still does traditionally, engaging in a two way communication with stakeholders of the HEIs using digital channels. In Level 3, HEI's has done a considerable amount of optimization, more 
than, perhaps, at Level 2, and they are trying to achieve more efficiencies through this digitalization whether it is in terms of supply chain and management, whether it is through marketing, but HEIs is connected through digitalization. In the last level, Level 4, this is about how the HEI's is looking at its future in terms of digitalization policy and strategy, and trying to compete on the basis of digital strategies.

\section{Method}

The aim of this study is to explore the common digital and social media marketing utilized by the top 25 universities in Asia \& Africa. It examined the reasons of using digital and social media marketing by higher education institutions and also it assessed the higher education institution level of adoption of digital technologies. The study used a descriptive type of research in which quantitative analysis was employed using the frequency count and percentage. The qualitative descriptive case study was used because it will not prove any hypothesis or model, but rather it will describe and explain the current situation of how HEIs in Asia and Africa are adopting to digital and social media marketing. Various web portals and social media pages provided by the top 25 universities in Asia and Africa was examined and observed to collect data. The respondents of this study were the top 25 universities in Asia and Africa based on the QS ranking of universities in Asia and web ranking in Africa in 2015.

\section{Results and Discussion}

The first objective of this study is to know the common digital and social media marketing used by the higher education institution in Asia and Africa. It considered the top 25 universities in Asia and Africa. Figure 1 and 2 reflects the common digital and social media marketing used by the top 25 universities of Asia and Africa. Figure 1 below shows that the majority of the top 25 universities in Asia are using Facebook which is $72 \%$, followed by YouTube, which is $68 \%$ and Twitter with $60 \%$, and LinkedIn is the least social media they used for digital and social media marketing.

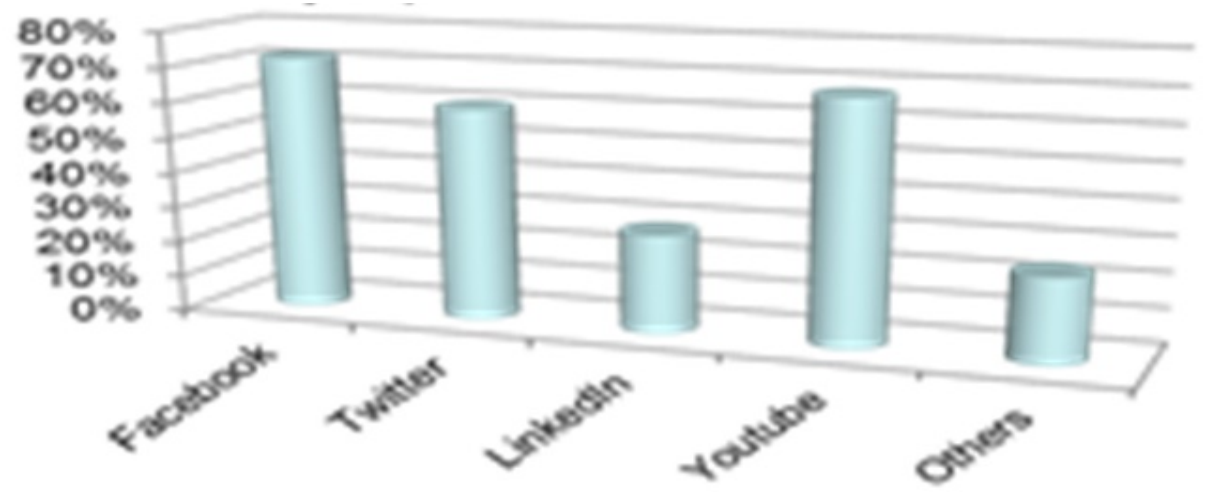

Figure 1. The common digital and social media marketing used by top 25 universities in Asia

Figure 2 displays the common digital and social media marketing utilized by the top 25 universities in Africa. Majority of the top 25 universities in Africa use Facebook $(76 \%)$, LinkedIn (72\%), Twitter (64\% and YouTube (52\%). 


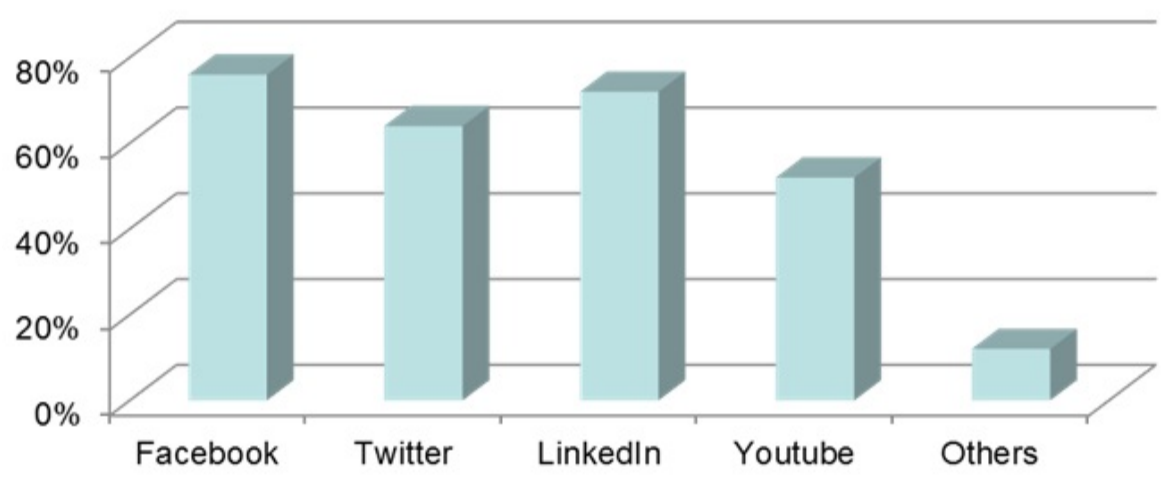

Figure 2. The common digital and social media marketing used by top 25 universities in Africa

The second objective of the study is to recognize the purposes why higher education institutions make use of digital and social media marketing. The collective responses are for recruitment campaign, marketing function and outreach campaign. To invite and encourage students most of the universities, nowadays social media like Facebook and Twitter are utilized. It was cost efficient to use this method on the part of the universities and it allows potential students to participate in social media. Normally, universities and school created an online community or social network as part of their online presence which they believe could bring together potential student with students who already enrolled where they could inquire about the experience of the current students of the universities or students who are looking for similar information and help. Universities believe that these activities appear to be an effective means of persuading the modern consumer. Good feedback of peers through social media such as blogs, social networks, forums and other forms are becoming an essential role in the decision making process among young persons. Lastly, it assessed the higher education institution's level of adoption of digital technologies. In assessing the different levels of digital technology adoption that HEIs go through, the model of Dr. Tahir Rashid levels of digital technology adoption were used. The majority of the top 25 universities in Asia is now in level 3, were the HEI's has done a considerable amount of improvement in their digital presence and they are trying to realize more efficiencies through this digitalization whether it is in terms of marketing and reach out with prospective students, but the universities are now connected through digitalization. As for the top 25 universities in Africa, the majority is still at level 1 were HEIs making some effort to have a digital presence for their academic programs and services. Some of the top 25 universities in Asia and Africa are in level 2 where they have more digital presence in terms of their academics programs and services. Furthermore, from the majority of level 3 of the top 25 universities in Asia they are now moving to level 4 where HEI's is more futuristic in terms of coming up of digitalization policy and strategy while for the top 25 universities in Africa some HEIs from level 2 are now moving to level 3 .

The following studies are similar to the result of the common digital and social media marketing utilized by the top 25 universities in Asia and Africa. First, was the study conducted by the University of Massachusetts Dartmouth in most of the universities in United State of America, it reflects that HEI's has a wider adoption of the following social 
media platforms: Facebook is the most common form of social networking being used, with 98\% of colleges and universities reported having a Facebook page; 84\% reported having some form of an institutional Twitter account; $86 \%$ reported having an institutional YouTube channel/ presence; $66 \%$ reported maintaining some kind of blog; $41 \%$ reported the use of podcasting; and $47 \%$ of admissions professionals reported using LinkedIn. Second, was the study by Slover-Linett and Stoner (2010), it reflects that most institutions used social media, with $94 \%$ use of Facebook. $60 \%$ of the institutions also used Twitter, LinkedIn, and/or YouTube. $96 \%$ used social media to communicate with alumni, while only about $57 \%$ used it as a marketing tool for perspective students. Lastly, the study in late 2010 with 30 international university admissions staff shows an inclination by institutes to use Facebook $(96 \%)$ and Twitter $(66 \%)$ as their outreach tools. 46\% used YouTube and 33\% used LinkedIn.

\section{Conclusion}

The results of the study show that top 25 universities in Asia and Africa are now utilizing digital and social media marketing. These are the similarities of the top 25 universities in Asia and Africa: first they used common digital and social media such as Facebook, twitter, LinkedIn, YouTube and others. Second, it reflects that the common purposes of using digital and social marketing for HEIs are to market their programs and to give information about events and research of the HEIs. It would be cost efficient for the HEIs to use digital and social media marketing for their marketing activities.

The difference between the top 25 universities in Asia and Africa are the following: first, in terms of frequency which digital and social media they utilized more as Facebook, YouTube and Twitter are the social media utilized by more of the top 25 universities in Asia, while the top 25 universities in Africa used more Facebook, LinkedIn and Twitter. Second is the level of digital adoption in HEIs in Asia and Africa. In Asia, the majority of the top 25 universities are now improving their digital technology presence online to integrate digitalization into their policy and strategies while the majority of top 25 universities in Africa has digital presence online for their academic programs and services aiming at more digital presence. Furthermore, most of the HEIs are using website design and interface as an essential factor on how to present themselves to their potential students.

\section{References}

Anyangwe, E. (2011). How to market higher education during times of change. The Guardian. Retrieved from http://www.guardian.co.uk/higher-educationnetwork/blog/2011/apr/06/higher-education-reputation-managementmarketing (Accessed 20 July 2016).

Arrington, M. (2011). MySpace stabilizes unique visitors, but all other usage stats plummet. Techcrunch. Retrieved from http://techcrunch.com/2011/05/11/myspace-stabilizesunique-visitors-but-all-other-usage-stats-plummet/ (Accessed 5 March 2016).

Barnes, N. G. (2010). The 2010 Inc. 500 update: Most blog, friend and tweet, but some industries still shun social media. Dartmouth, USA: University of Massachusetts, Center for Marketing Research.

Ganim-Barnes, N., \& Mattson, E. (2009). Social media and college admissions: Higher-ed beats business in adoption of new tools for third year. University of Massachusetts Center for Marketing Research. Retrieved from http://www.umassd.edu/media/umassdartmouth/cmr/studiesandresearch/socialmediaadmissions.pdf. (Accessed $10 \mathrm{March}$ 2016).

Constantinides, E. (2010). Connecting small and medium enterprises to the new consumer: The web 2.0 as marketing tool global perspectives on small and medium enterprise. Hershey, Pennsylvania: IGI Global. 
Constantinides, E., \& Zinck-Stagno, M. (2011). Potential of the social media as instruments of higher education marketing: A segmentation study. Journal of Marketing for Higher Education, 21(1), 7-24.

DigitalBuzz. (2012). Facebook statistics, stats \& facts for 2011. Retrieved from http://www.digitalbuzzblog.com/facebookstatistics-stats-facts-2011/ (Accessed 10 March 2016).

Gilroy, M. (2012). Higher education migrates to YouTube and Social Networks. The Education Digest, 75(7), 18-22.

Griffiths, P., \& Wall, A. (2011). Social media use by enrollment management. In L. Wankel \& C. Wankel (Eds.), Higher education administration with social media (pp. 49-70). United Kingdom: Emerald Group Publishing.

Hanover Research. (2014). Trends in higher education marketing, recruitment and technology (Report). March 2014. Retrieved from https://www.hanoverresearch.com/

Hayes, T. J., Ruschman, D., \& Walker, M. M. (2009). Social networking as an admission tool: A case study in success. Journal of Marketing for Higher Education, 19(2), 109-124.

Kowalik, E. (2011). Engaging alumni and prospective students through social media. In L. Wankel \& C. Wankel (Eds.), Higher education administration with social media (pp.211-227). United Kingdom: Emerald Group Publishing.

Lewis, B. (2010). Social media and strategic communication: Attitudes and perceptions among college students. Public Relations Journal, 4(3), 1-23.

LinkedIn. (2012). Higher education today. Retrieved from http://www.linkedin.com/today/higher_education (Accessed 5 April 2016).

Mandelson, P. (2009). Higher ambitions: The future of universities in a knowledge economy. London, England: Department for Business, Innovation and Skills.

Mansfield, H. (2009). 10 Twitter tips for higher education. University Business Magazine. Retrieved from http://www.universitybusiness.com/article/10-twitter-tips-highereducation (Accessed 10 April 2016).

Merrill, N. (2011). Social media for social research: Applications for higher education communications. In L. Wankel \& C. Wankel (Eds.), Higher education administration with social media (pp. 25-48). United Kingdom: Emerald Group Publishing.

Pearson Education (2010). First-of-its-kind survey finds college faculty increasingly using social media. Retrieved from http://www.pearsoned.com/sociable-professors/ (Accessed 20 April 2016).

Ratliff, A. (2011). Are they listening? Social media on campuses of higher education. The Journal of the Australian and New Zealand Student Services Association, 38, 65-69.

Reuben, R. (2008). The use of social media in higher education for marketing and communications: A guide for professionals in higher education. Rachelreuben. Retrieved form https://www.rachelreuben.com/2008/08/19/social-mediauses-higher-education-marketing-communication/ (Accessed 20 April 2016).

Slover-Linett, C., \& Stoner, M. (2010). Succeeding with social media: Lessons from the first survey of social media. Slover Linett Issue Paper Series, 1-37. Retrieved from http://www.sloverlinett.com/files/mStonerSloverLinett\%20White\%20Paper.pdf (Accessed 2 July 2016).

Social Media Today. (2011). Who Uses Facebook, Twitter, LinkedIn, \& MySpace? 4thQ \& 1stQ Stats and Analysis. Retrieved from http://socialmediatoday.com/paulkiser/285851/who-uses-facebook-twitter-linkedinmyspace-4thq-1 stqstats-and-analysis (Accessed 10 April 2016).

Wikipedia. (2012). List of social networking websites. Retrieved from http://en.wikipedia.org/wiki/List_of_social_networking_websites. (Accessed 10 April 2016).

Wheeler, D. (2012). New twists in online recruiting of international students. The Chronicle of Higher Education. Retrieved from http://chronicle.com/blogs/planet/2012/04/08/new-twists-in-online-recruitingof-international-students/ (Accessed 25 April 2016).

Wootton, R. (2011). Survey shows educational institutions increasingly going online to reach and attract students. University Business News. Retrieved from http://www.universitybusiness.com/news/survey-showseducational-institutionsincreasingly-going-online-reach-and-attract-students (Accessed 2 May 2016). 